\title{
Roles of Ion and Water Channels in the Cell Death and Survival of Upper Gastrointestinal Tract Cancers
}

\author{
Atsushi Shiozaki ${ }^{1 *}$, Yoshinori Marunaka ${ }^{2,3,4}$ and Eigo Otsuji ${ }^{1}$ \\ ${ }^{1}$ Division of Digestive Surgery, Department of Surgery, Kyoto Prefectural University of Medicine, Kyoto, Japan, ${ }^{2}$ Department \\ of Molecular Cell Physiology, Graduate School of Medical Science, Kyoto Prefectural University of Medicine, Kyoto, Japan, \\ ${ }^{3}$ Research Institute for Clinical Physiology, Kyoto Industrial Health Association, Kyoto, Japan, ${ }^{4}$ Research Center for Drug \\ Discovery and Pharmaceutical Development Science, Research Organization of Science and Technology, Ritsumeikan \\ University, Kusatsu, Japan
}

OPEN ACCESS

Edited by: Giovanna Valenti,

University of Bari Aldo Moro, Italy

Reviewed by:

Darren Finlay,

Sanford Burnham Institute for Medical Research, United States

Shutao Zheng,

Xinjiang Medical University, China

Giorgio Santoni,

University of Camerino, Italy

*Correspondence:

Atsushi Shiozak

shiozaki@koto.kpu-m.ac.jp

Specialty section:

This article was submitted to

Cell Death and Survival,

a section of the journal

Frontiers in Cell and Developmental

Biology

Received: 13 October 2020

Accepted: 22 February 2021

Published: 11 March 2021

Citation:

Shiozaki A, Marunaka Y and Otsuji E (2021) Roles of lon and Water

Channels in the Cell Death and Survival of Upper Gastrointestinal

Tract Cancers.

Front. Cell Dev. Biol. 9:616933. doi: 10.3389/fcell.2021.616933
Ion and water channels were recently shown to be involved in cancer cell functions, and various transporter types have been detected in upper gastrointestinal tract (UGl) cancers. Current information on the expression and roles of these channels and transporters in the death and survival of UGI cancer cells was reviewed herein, and the potential of their regulation for cancer management was investigated. Esophageal cancer (EC) and gastric cancer (GC) cells and tissues express many different types of ion channels, including voltage-gated $\mathrm{K}^{+}, \mathrm{Cl}^{-}$, and $\mathrm{Ca}^{2+}$, and transient receptor potential (TRP) channels, which regulate the progression of cancer. Aquaporin (AQP) 1, 3, and 5 are water channels that contribute to the progression of esophageal squamous cell carcinoma (ESCC) and GC. Intracellular $\mathrm{pH}$ regulators, including the anion exchanger (AE), sodium hydrogen exchanger (NHE), and vacuolar $\mathrm{H}^{+}$-ATPases (V-ATPase), also play roles in the functions of UGI cancer cells. We have previously conducted gene expression profiling and revealed that the regulatory mechanisms underlying apoptosis in ESCC cells involved various types of $\mathrm{Cl}^{-}$channels, $\mathrm{Ca}^{2+}$ channels, water channels, and $\mathrm{pH}$ regulators (Shimizu et al., 2014; Ariyoshi et al., 2017; Shiozaki et al., 2017, 2018a; Kobayashi et al., 2018; Yamazato et al., 2018; Konishi et al., 2019; Kudou et al., 2019; Katsurahara et al., 2020, 2021; Matsumoto et al., 2021; Mitsuda et al., 2021). We have also previously demonstrated the clinicopathological and prognostic significance of their expression in ESCC patients, and shown that their pharmacological blockage and gene silencing had an impact on carcinogenesis, indicating their potential as targets for the treatment of UGI cancers. A more detailed understanding of the molecular regulatory mechanisms underlying cell death and survival of UGl cancers may result in the application of cellular physiological methods as novel therapeutic approaches.

Keywords: esophageal cancer, gastric cancer, ion channels, water channels, intracellular pH

\section{INTRODUCTION}

Upper gastrointestinal tract (UGI) cancers, such as esophageal cancer (EC) and gastric cancer (GC), have high recurrence rates and are one of the leading causes of cancer-related death globally (Kamangar et al., 2006; Brenner et al., 2009; Hartgrink et al., 2009). EC is the ninth most common cancer and the sixth most common cause of cancer deaths worldwide, and GC is the sixth 
most common cancer and the third most common cause of cancer deaths (Bray et al., 2018). The vast majority of ECs are either esophageal squamous cell carcinoma (ESCC) or esophageal adenocarcinomas (EAC). Although the prognosis of patients with UGI cancers has recently been improved by advances in surgical techniques, chemotherapy, radiotherapy, immunotherapy, and molecular targeted therapy (Jemal et al., 2011; Udagawa et al., 2012; Nashimoto et al., 2013; Tachimori et al., 2019), they remain poor, particularly for patients with advanced disease. Limited information is currently available on the efficacy of potential drug combinations against EC and GC because of the ability of these cells to evade apoptosis. Therefore, further studies on the molecular mechanisms regulating the cell death and survival of UGI cancers are needed for the development of more effective treatments.

Ion and water channels/transporters have important roles in cellular functions. Their physiological contribution to cell death and survival is crucial because cell volume changes, which require the movement of ions and water molecules across cell membranes, are critical for apoptosis (Okada et al., 2001, 2006). The involvement of ion and water channels in cancer cell functions was recently demonstrated, and thus, their regulation has potential as a novel strategy in cancer therapies (Pedersen and Stock, 2013; Pardo and Stuhmer, 2014; Shiozaki et al., 2014; Lastraioli et al., 2015; Nagaraju et al., 2016; Xia et al., 2017; Anderson et al., 2019).

Current information on the functions of ion and water channels in the cell death and survival of UGI cancers was systematically reviewed herein. The main aim of this review was to investigate the potential of cellular physiological strategies, such as the regulation of ion channels, water channels, and $\mathrm{pH}$ regulators, in the clinical management of EC and GC.

\section{Potassium $\left(\mathrm{K}^{+}\right)$Channels}

Several subtypes of $\mathrm{K}^{+}$channels were recently shown to be expressed in human EC and GC cells and play important roles in cell death and survival (Table 1). The expression of several voltage-gated $\mathrm{K}^{+}$channels $(\mathrm{Kv})$ is modified in UGI cancers. Han et al. (2007) reported that the up-regulated expression of potassium voltage-gated channel, shaker-related subfamily, member 5 (KCNA5), also known as Kv1.5, increased $\mathrm{K}^{+}$current density as well as GC cell sensitivity to multiple chemotherapeutic drugs by regulating drug-induced apoptosis. Furthermore, a component of the delayed rectifier $\mathrm{K}^{+}$current was found to be encoded by the human ether-a-go-go-related gene (HERG). The expression of HERG channels was shown to be limited in GC, and the HERG channel blocker, cisapride, and genetic knockdown by small interfering RNA (siRNA) technology induced apoptosis (Shao et al., 2005, 2008). Zhang et al. (2012) demonstrated that the expression of HERG was crucial for the cisplatinmediated induction of apoptosis in human GC. However, in these studies, molecular mechanisms of the regulation of apoptosis via HERG had not been shown in detail. Instead, HERG1 expression was found to regulate apoptosis in ESCC through thioredoxin domain-containing protein 5 (TXNDC5) by activating the phosphatidylinositol-3 kinase (PI3K)/Akt pathway (Wang et al., 2019). Yu et al. (2020) reported that the overexpression of the long non-coding RNA (lncRNA), heart and neural crest derivatives expressed 2 antisense RNA 1 (HAND2AS1) promoted apoptosis in GC cells, and showed that it bound with miR-590-3p to alter the expression of potassium sodiumactivated channel subfamily $\mathrm{T}$ member 2 (KCNT2). Potassium channel subfamily $\mathrm{K}$ member 9 (TASK-3) (KCNK9 or K2P9.1) is a $\mathrm{K}^{+}$channel from the $\mathrm{K}_{2 P}$ family that forms functional homoor heterodimers (Enyedi and Czirjak, 2010). Cikutović-Molina et al. (2019) recently showed that the knockdown of the TASK-3 gene promoted apoptosis in KATO III and MKN-45 human GC cell lines. The protein encoded by potassium calcium-activated channel Subfamily M Alpha 1 (KCNMA1) is a voltage- and $\mathrm{Ca}^{2+}$ activated $\mathrm{K}^{+}$channel. Ma et al. (2017) found that KCNMA1 significantly inhibited the biological malignant behavior of GC cells in vitro by inducing apoptosis, and suppressed xenograft tumor growth in subcutaneous mouse models. The importance of this study was to reveal that the anti-tumor effect of KCNMA1was mediated through suppressing the expression of the key apoptosis gene protein tyrosine kinase 2 (PTK2).

Collectively, these findings clearly demonstrate the involvement of $\mathrm{K}^{+}$channels in the apoptosis of ESCC and GC cells, and thus, further studies on their clinical potential are warranted.

\section{Chloride $\left(\mathrm{Cl}^{-}\right)$Channels}

$\mathrm{Cl}^{-}$channels play a role in the cell death and survival of UGI cancers (Table 2). Ma et al. (2012) reported that the strong expression of chloride intracellular channel 1 (CLIC1) suppressed the proliferation of GC cells and promoted their apoptosis, migration, and invasion. Li et al. (2018) also demonstrated that the genetic knockdown of CLIC1 by siRNA technology strongly induced apoptosis in GC cells by regulating the mitogen-activated protein kinase $(\mathrm{MAPK}) /$ protein kinase $\mathrm{B}$

TABLE 1 | Overview of potassium channels with roles in the cell death and survival of upper gastrointestinal tract cancers.

\begin{tabular}{|c|c|c|c|c|}
\hline Channels & Organ & $\begin{array}{c}\text { Mechanism/ } \\
\text { pathway }\end{array}$ & Induction & References \\
\hline KCNA5 & $\mathrm{GC}$ & & $\begin{array}{l}\text { Aminopyridine, } \\
\text { tetraethylammonium }\end{array}$ & Han et al., 2007 \\
\hline \multirow[t]{3}{*}{ HERG } & GC & & Cisapride & $\begin{array}{c}\text { Shao et al., } \\
2005\end{array}$ \\
\hline & GC & & siRNA technology & $\begin{array}{c}\text { Shao et al., } \\
2008\end{array}$ \\
\hline & GC & & siRNA technology & $\begin{array}{l}\text { Zhang et al., } \\
\qquad 2012\end{array}$ \\
\hline HERG1 & ESCC & $\begin{array}{c}\text { TXNDC5, } \\
\text { PI3K/AKT pathway }\end{array}$ & shRNA technology & $\begin{array}{l}\text { Wang et al., } \\
2019\end{array}$ \\
\hline KCNT2 & $\mathrm{GC}$ & $\begin{array}{l}\text { HAND2-AS1, } \\
\text { miR-590-3p }\end{array}$ & $\begin{array}{l}\text { overexpression } \\
\text { vector }\end{array}$ & Yu et al., 2020 \\
\hline KCNK9 & $\mathrm{GC}$ & & siRNA technology & $\begin{array}{l}\text { Cikutović- } \\
\text { Molina et al., } \\
2019\end{array}$ \\
\hline KCNMA1 & GC & PTK2 & $\begin{array}{l}\text { Overexpression } \\
\text { plasmid }\end{array}$ & Ma et al., 2017 \\
\hline
\end{tabular}

ESCC, esophageal squamous cell carcinoma; GC, gastric cancer. 
TABLE 2 | Overview of chloride channels with roles in the cell death and survival of upper gastrointestinal tract cancers.

\begin{tabular}{|c|c|c|c|c|}
\hline Channels & Organ & $\begin{array}{c}\text { Mechanism/ } \\
\text { pathway }\end{array}$ & Induction & References \\
\hline \multirow[t]{4}{*}{ CLIC1 } & ESCC & TLR2/JNK pathway & siRNA technology & $\begin{array}{l}\text { Kobayashi } \\
\text { et al., } 2018\end{array}$ \\
\hline & GC & & siRNA technology & Ma et al., 2012 \\
\hline & $\mathrm{GC}$ & $\begin{array}{c}\text { PI3K/AKT, } \\
\text { MAPK/ERK, and } \\
\text { MAPK/p38 } \\
\text { pathways }\end{array}$ & siRNA technology & Li et al., 2018 \\
\hline & GC & $\begin{array}{c}\text { Exosome-mediated } \\
\text { transfer }\end{array}$ & siRNA technology & $\begin{array}{c}\text { Zhao et al., } \\
2019\end{array}$ \\
\hline \multirow[t]{2}{*}{ ANO1 } & GC & & 3n, Ani-FCC & Seo et al., 2020 \\
\hline & GC & $\begin{array}{c}\text { LncRNA OIP5-AS1 } \\
\text { miR-422a }\end{array}$ & RNA interference & Xie et al., 2020 \\
\hline \multirow[t]{2}{*}{ ANO9 } & ESCC & $\begin{array}{l}\text { Centrosome- } \\
\text { related } \\
\text { genes }\end{array}$ & siRNA technology & $\begin{array}{l}\text { Katsurahara } \\
\text { et al., } 2020\end{array}$ \\
\hline & GC & $\begin{array}{l}\text { IFN signaling, } \\
\text { PD-L2 }\end{array}$ & siRNA technology & $\begin{array}{l}\text { Katsurahara } \\
\text { et al., } 2021\end{array}$ \\
\hline CLCN2 & ESCC & IFN signaling & $\begin{array}{c}\text { Lubiprostone, } \\
\text { overexpression } \\
\text { plasmid }\end{array}$ & $\begin{array}{c}\text { Mitsuda et al., } \\
2021\end{array}$ \\
\hline CFTR & ESCC & $\begin{array}{l}\text { p38 signaling } \\
\text { pathway }\end{array}$ & $\begin{array}{l}\text { Overexpression } \\
\text { plasmid }\end{array}$ & $\begin{array}{l}\text { Matsumoto } \\
\text { et al., } 2021\end{array}$ \\
\hline LRRC8A & ESCC & $\begin{array}{c}\text { Phosphatidylinositol } \\
\text { 3-kinase/AKT } \\
\text { signaling }\end{array}$ & siRNA technology & $\begin{array}{l}\text { Konishi et al., } \\
2019\end{array}$ \\
\hline
\end{tabular}

ESCC, esophageal squamous cell carcinoma; GC, gastric cancer.

(Akt) pathways. Zhao et al. (2019) described a role for exosomemediated transfer of CLIC1 in vincristine resistance via the regulation of $\mathrm{P}$-gp and $\mathrm{B}$-cell lymphoma 2 (Bcl-2) in GC cells. We previously reported the induction of apoptosis in ESCC via the Toll-like receptor 2 (TLR2)/c-Jun N-terminal kinase (JNK) pathway by the genetic knockdown of CLIC1 with siRNA technology (Kobayashi et al., 2018). The anoctamin family consists of transmembrane proteins in 10 isoforms, and the best-known anoctamin gene is anoctamin 1 (ANO1), a $\mathrm{Cl}^{-}$ channel activated by $\mathrm{Ca}^{2+}$ (Schreiber et al., 2010). Seo et al. (2020) showed that 3n, Ani-FCC, a novel, potent, and selective ANO1 inhibitor, significantly enhanced apoptosis by activating caspase 3 and cleaving poly (ADP-ribose) polymerase (PARP) in GC cells. Xie et al. (2020) reported that long non-coding RNA (lncRNA) OPA-interacting protein 5 antisense transcript 1 (OIP5-AS1) regulated apoptosis in GC by targeting the microRNA (miR)-422a/ANO1 axis. We recently demonstrated that the genetic knockdown of ANO9 by siRNA technology increased apoptosis in ESCC cells (Katsurahara et al., 2020). Moreover, the findings of our microarray analysis indicated that the expression of a number of centrosome-related genes, such as centrosomal protein 120 (CEP120), CNTRL, and SPAST, was up- or down-regulated in ANO9-depleted KYSE150 cells, while immunohistochemistry (IHC) showed that the strong expression of ANO9 was associated with a poor prognosis in ESCC patients (Katsurahara et al., 2020). Over the past decade, one of the most important breakthroughs in cancer treatment has been immune checkpoint blockage (ICB) of programmed cell death-1 (PD-1). In GC, we have observed tumor suppressive effects following the genetic knockdown of ANO9 with siRNA technology, such as decreased proliferation, and increased apoptosis (Katsurahara et al., 2021). The results of microarray and IHC indicated that ANO9 regulates programmed cell death 1 ligand 2 (PD-L2) and binding ability to PD-1 via interferon (IFN)-related genes, suggesting that ANO9 has potential as a biomarker and target of ICB for GC. Leucinerich repeat-containing protein 8A (LRRC8A) is a ubiquitous and integral component of the volume-regulated anion channel, which is required for the regulation of cell volume (Qiu et al., 2014). We reported that the depletion of LRRC8A promoted apoptosis in ESCC cells, microarray data revealed the altered regulation of phosphatidylinositol-3 kinase (PI3K)/Akt signaling in LRRC8A-depleted cells, and IHC showed that the strong LRRC8A expression correlated with a poorer prognosis in ESCC patients (Konishi et al., 2019). Chloride channel 2 (CLCN2) is a member of the CLC family, which is an inwardly rectifying chloride channel. We also demonstrated that downregulated expression of CLCN2 decreased apoptosis, whereas its upregulation increased it in ESCC cells (Mitsuda et al., 2021). The effects of lubiprostone, a CLCN2 activator, were also investigated, and apoptosis was increased in lubiprostonetreated ESCC cells. The results of microarray and IHC indicated that tumor progression is regulated by CLCN2 through its effects on IFN signaling, and that weak CLCN2 expression was associated with poorer outcomes in ESCC patients. Lubiprostone is used in the management of idiopathic chronic constipation in patients with various cancers, particularly those using opioid analgesics. Lubiprostone functioned as a pharmacological activator of CLCN2, and enhanced the inhibitory effects of cisplatin (CDDP) in ESCC cells (Mitsuda et al., 2021), suggesting the potential of its clinical application for ESCC. The cystic fibrosis transmembrane conductance regulator (CFTR) is a cyclic AMP-dependent chloride anion conducting channel, and inactivating germline mutations in CFTR cause the cystic-fibrosis (CF), which is the most common autosomal recessive hereditary disease among Caucasians. We have recently demonstrated that the overexpression of CFTR induced apoptosis in ESCC via activation of the p38 signaling pathway and was associated with a good patient prognosis (Matsumoto et al., 2021). The relationship between the incidence of cancer and genetic variations in the CFTR gene has been attracting increasing attention because $\mathrm{CF}$ patients are at a significantly higher risk of developing various cancers. Our results may explain the molecular mechanism of this clinical features and indicate the potential of CFTR as a mediator of and/or a biomarker for ESCC. Further, lubiprostone is also known as the CFTR activator, suggesting the future prospects of therapeutic strategies targeting CFTR against ESCC patients. Mechanism of apoptosis regulation via these $\mathrm{Cl}^{-}$channels in ESCC cell were summarized in Figure 1.

Collectively, these findings indicate the important roles of $\mathrm{Cl}^{-}$ channels in the apoptosis of UGI cancer cells and the potential of CLIC1, ANO1, ANO9, and LRRC8A as therapeutic targets against ESCC and GC. 


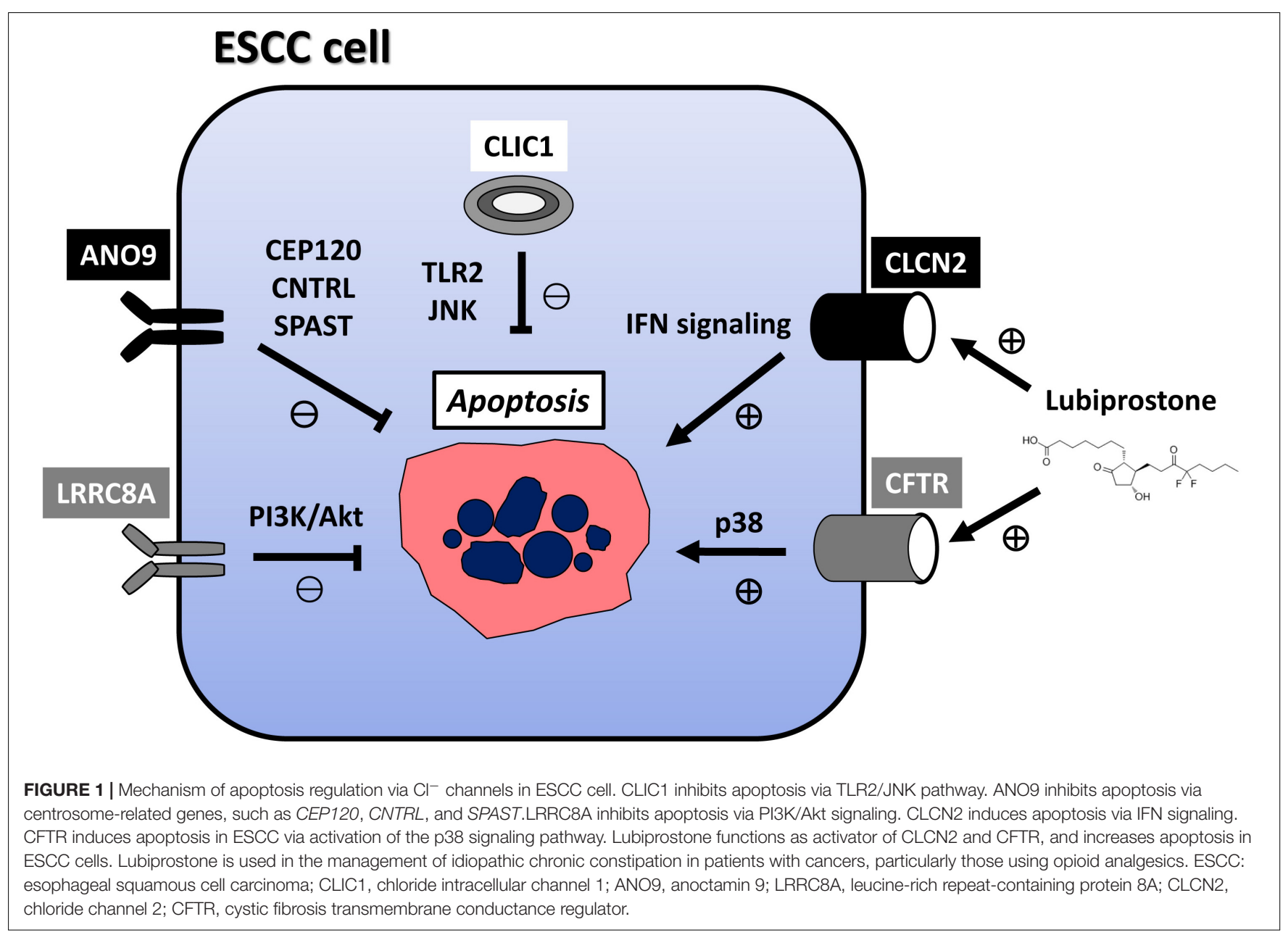

\section{Calcium $\left(\mathrm{Ca}^{2+}\right)$ Channels}

$\mathrm{Ca}^{2+}$ channels participate in regulation of intracellular $\mathrm{Ca}^{2+}$ concentrations $\left(\left[\mathrm{Ca}^{2+}\right]_{\mathrm{i}}\right)$, and play important roles in the cell death and survival of UGI cancers (Table 3). The transient receptor potential (TRP) superfamily comprises a very diverse group of ion channels, most of which exhibit permeability to monovalent and divalent cations. TRP family members are divided into seven subfamilies, such as classical (TRPC), vanilloid receptor-related (TRPV), and melastatin-related (TRPM) channels. Ding et al. (2018) previously demonstrated that pyrazolo[1,5-a]pyrimidine TRPC6 antagonists suppressed the proliferation of GC cells, and this anti-tumor effect on GC was confirmed in xenograft models using nude mice. We also recently reported that the genetic knockdown of TRPV2 by siRNA technology induced apoptosis in ESCC. A pathway analysis of microarray data showed that the depletion of TRPV2 down-regulated WNT/ $\beta$-catenin signaling-related genes, and an IHC analysis revealed a correlation between strong TRPV2 expression and a poor prognosis in ESCC patients (Kudou et al., 2019). We also demonstrated the overexpression of TRPV2 in cancer stem cells (CSCs) derived from ESCC, and suggested the potential of tranilast, a TRPV2-specific inhibitor, as a therapeutic agent against CSCs (Shiozaki et al., 2018b).
Tranilast has been used to treat patients with inflammatory diseases, such as asthma, dermatitis, allergic conjunctivitis, keloids, and hypertrophic scars, and its safety for clinical use has already been demonstrated. Preoperative adjuvant chemotherapy with CDDP and 5-fluorouracil (5FU) is currently used with beneficial effects to treat localized advanced ESCC in Japan (Ando et al., 2012). To confirm the clinical safety and efficacy of the additional use of tranilast with neoadjuvant 5-FU/CDDP, and to develop a novel therapeutic strategy for patients with advanced ESCC, we designed phase I/II study, and it is ongoing (Shiozaki et al., 2020). Chow et al. (2007) showed that TRPV6 mediated capsaicin-induced apoptosis in GC cells and also that capsaicin induced apoptosis by stabilizing p53 through the activation of JNK. Almasi et al. (2018) reported that the TRPM2 channel-mediated regulation of autophagy maintained mitochondrial function and promoted GC cell survival via the JNK signaling pathway. Quercetin induced apoptosis in GC cells by inhibiting MAPKs and TRPM7 channels (Kim et al., 2014). Calcium channel, voltage-dependent, alpha $2 /$ delta subunit 3 (CACNA2D3) is an auxiliary member of the alpha-2/delta subunit family of the voltage-dependent $\mathrm{Ca}^{2+}$ channel complex. Li et al. (2013) reported the down-regulation of CACNA2D3 in $56.7 \%$ of ESCC, which correlated with lymph node metastasis, 
TABLE 3 | Overview of calcium channels with roles in the cell death and survival of upper gastrointestinal tract cancers.

\begin{tabular}{|c|c|c|c|c|}
\hline Channels & Organ & $\begin{array}{c}\text { Mechanism/ } \\
\text { pathway }\end{array}$ & Induction & References \\
\hline TRPC6 & $\mathrm{GC}$ & & $\begin{array}{c}\text { Pyrazolo[1,5- } \\
\text { a]pyrimidine }\end{array}$ & $\begin{array}{c}\text { Ding et al., } \\
2018\end{array}$ \\
\hline TRPV2 & ESCC & $\begin{array}{l}\text { WNT/ } \beta \text {-catenin } \\
\text { signaling, Cancer } \\
\text { stem cells }\end{array}$ & $\begin{array}{c}\text { Tranilast, siRNA } \\
\text { technology }\end{array}$ & $\begin{array}{l}\text { Kudou et al., } \\
2019\end{array}$ \\
\hline TRPV6 & GC & Bax, p53, JNK & $\begin{array}{l}\text { Capsaicin, } \\
\text { overexpression } \\
\text { plasmid }\end{array}$ & $\begin{array}{c}\text { Chow et al., } \\
2007\end{array}$ \\
\hline TRPM2 & GC & $\begin{array}{l}\text { JNK signaling } \\
\text { pathway }\end{array}$ & shRNA technology & $\begin{array}{c}\text { Almasi et al., } \\
2018\end{array}$ \\
\hline TRPM7 & $\mathrm{GC}$ & MAPK & Quercetin & Kim et al., 2014 \\
\hline CACNA2D1 & GC & Cancer stem cells & Amlodipine & $\begin{array}{c}\text { Shiozaki et al., } \\
2021\end{array}$ \\
\hline \multirow[t]{2}{*}{ CACNA2D3 } & ESCC & $\begin{array}{l}\text { Up-regulate } \\
\text { intracellular free } \\
\text { cytosolic } \mathrm{Ca}^{2+}\end{array}$ & $\begin{array}{c}\text { Overexpression } \\
\text { vector }\end{array}$ & Li et al., 2013 \\
\hline & ESCC & $\begin{array}{c}\mathrm{Ca}^{2+} \text {-mediated } \\
\text { apoptosis, } \\
\text { PI3K/Akt pathways }\end{array}$ & $\begin{array}{l}\text { Cisplatin, } \\
\text { overexpression } \\
\text { plasmid }\end{array}$ & Nie et al., 2019 \\
\hline CACNB4 & GC & Cancer stem cells & Verapamil & $\begin{array}{c}\text { Shiozaki et al., } \\
2021\end{array}$ \\
\hline
\end{tabular}

ESCC, esophageal squamous cell carcinoma; GC, gastric cancer.

TNM staging, and the poor outcomes of ESCC patients, and suggested that CACNA2D3 up-regulates intracellular cytosolic $\mathrm{Ca}^{2+}$, thereby inducing apoptosis. Nie et al. (2019) demonstrated that CACNA2D3 enhanced the chemosensitivity of ESCC to cisplatin by inducing $\mathrm{Ca}^{2+}$-mediated apoptosis and suppressing the PI3K/Akt pathways. Recently, we have demonstrated that voltage-gated $\mathrm{Ca}^{2+}$ channels (VGCCs), including calcium voltage-gated channel auxiliary subunit alpha2delta 1 (CACNA2D1) and calcium voltage-gated channel auxiliary subunit beta 4 (CACNB4), were strongly expressed in gastric CSCs (Shiozaki et al., 2021). The cytotoxicities of the CACNA2D1 inhibitor amlodipine and the CACNB4 inhibitor verapamil were greater at lower concentrations in CSCs than in non-CSCs. Amlodipine, a specific inhibitor of CACNA2D1, has been widely used in the treatment of hypertension and cardiac angina. Verapamil, a specific inhibitor of CACNB4, has been widely used in the treatment of arrhythmia. These results indicate that VGCCs play a role in maintaining CSCs, and demonstrated the potential of their specific inhibitors as targeted therapeutic agents against GC.

These findings clearly demonstrate that $\mathrm{Ca}^{2+}$ channels contribute to UGI cancer cell death, and thus, future studies are needed on their clinical potential.

\section{Water Channels}

Under physiological and pathophysiological conditions, the volume of cells is regulated and the electrolyte balance is maintained by aquaporins (AQPs), which are transmembrane proteins that facilitate water transport. Thirteen AQP subtypes have so far been identified in humans and their functions have been elucidated. AQPs have also been shown to play important roles in the cell death and survival of UGI cancers (Table 4). We recently demonstrated the induction of apoptosis in ESCC cells by the genetic knockdown of AQP1 with siRNA technology, alterations in Death receptor signaling pathwayrelated genes in AQP1-depleted TE5 cells by a microarray analysis, and a correlation between the cytoplasmic dominant expression of AQP1 and a poor prognosis in patients with ESCC by IHC (Yamazato et al., 2018). Sun et al. (2016) reported that AQP1 expression in GC was associated with apoptosis and the survival of patients, however, molecular mechanisms of the regulation of apoptosis via AQP1 had not been shown in detail. Kusayama et al. (2011) attributed cell death in ESCC due to the genetic knockdown of AQP3 by siRNA technology to the direct interference of cell adhesion involving the intracellular focal adhesion kinase (FAK)MAPK signaling pathways. Several studies demonstrating the regulatory mechanisms via $\mathrm{miR}$ were valuable. Jiang et al. (2014) demonstrated that the down-regulation of Bcl-2 and upregulation of caspase- 3 activity and $\mathrm{Bcl}-2$-associated $\mathrm{X}$ protein (Bax) were involved in the induction of cell apoptosis in GC cells by miR-874 through the targeting of AQP3. Furthermore, Zhu et al. (2020) showed that the up-regulated expression of miR-877 promoted apoptosis in GC cells, and luciferase reporter assays revealed that AQP3 was a direct downstream target of miR-877. We also demonstrated that the genetic knockdown of AQP5 by siRNA technology induced apoptosis in ESCC cells, while a microarray analysis identified tumor protein p53-induced nuclear protein 1 (TP53INP1) as one of the top ranking up-regulated genes widely known as the gene related to cell apoptosis in AQP5-depleted ESCC cells (Shimizu et al., 2014). IHC staining of samples collected from ESCC patients revealed relationships between the expression of AQP5 and tumor size, histological type, and tumor recurrence (Shimizu et al., 2014).

Therefore, AQPs appear to be crucially involved in the cell death and survival of ESCC and GC, and these findings indicate the potential of $\mathrm{AQP} 1,3$, and 5 as therapeutic targets in UGI cancers.

TABLE 4 | Overview of water channels with roles in the cell death and survival of upper gastrointestinal tract cancers.

\begin{tabular}{|c|c|c|c|c|}
\hline Channels & Organ & $\begin{array}{c}\text { Mechanism/ } \\
\text { pathway }\end{array}$ & Induction & References \\
\hline \multirow[t]{2}{*}{ AQP1 } & ESCC & $\begin{array}{c}\text { Death receptor } \\
\text { signaling pathway }\end{array}$ & siRNA technology & $\begin{array}{l}\text { Yamazato } \\
\text { et al., } 2018\end{array}$ \\
\hline & $\mathrm{GC}$ & Apoptosis & & Sun et al., 2016 \\
\hline \multirow[t]{3}{*}{ AQP3 } & ESCC & $\begin{array}{c}\text { FAK-MAPK } \\
\text { signaling pathways }\end{array}$ & $\begin{array}{l}\text { pan-AQP inhibitor, } \\
\text { siRNA technology }\end{array}$ & $\begin{array}{l}\text { Kusayama } \\
\text { et al., } 2011\end{array}$ \\
\hline & $\mathrm{GC}$ & miR-874 & $\begin{array}{l}\text { Overexpression } \\
\text { vector }\end{array}$ & $\begin{array}{l}\text { Jiang et al., } \\
2014\end{array}$ \\
\hline & $\mathrm{GC}$ & miR-877 & miRNA mimics & Zhu et al., 2020 \\
\hline AQP5 & ESCC & p53 & siRNA technology & $\begin{array}{c}\text { Shimizu et al., } \\
2014\end{array}$ \\
\hline
\end{tabular}

ESCC, esophageal squamous cell carcinoma; GC, gastric cancer. 


\section{pH Regulators}

The regulation of cytoplasmic $\mathrm{pH}$ by ion transporters was recently shown to be important for tumor cell functions. $\mathrm{pH}$ regulators, including the anion exchanger $(\mathrm{AE}), \mathrm{Na}^{+} / \mathrm{H}^{+}$ exchanger (NHE), and vacuolar $\mathrm{H}^{+}$-ATPase (V-ATPase), directly contribute to maintaining the tumor microenvironment, and play critical roles in the cell death and survival of UGI cancers (Table 5). The electroneutral exchange of $\mathrm{Cl}^{-}$for $\mathrm{HCO}_{3}{ }^{-}$across the plasma membrane of mammalian cells is facilitated by $\mathrm{AE}$ proteins and maintains intracellular $\mathrm{pH}$. Three AE isoforms have been identified: AE1, AE2, and AE3. Shen et al. (2007) showed that the genetic knockdown of AE1 by siRNA technology in GC cells induced the release of p16 from the cytoplasm to the nucleus, leading to the death of tumor cells. Importantly, the transfection with miR-24 induced the return of p16 to the nucleus, confirming the miR-24-controlled AE1 down-regulation in GC (Wu et al., 2010). We performed IHC on primary tumor samples obtained from ESCC patients and found that significantly fewer samples exhibited diffuse AE1 expression than focal expression (Shiozaki et al., 2017). In addition, the genetic knockdown of AE1 by siRNA technology induced apoptosis, and a microarray analysis of AE1depleted ESCC cells showed the down-regulated expression of MAPK and Hedgehog signaling pathway-related genes (Shiozaki et al., 2017). However, we subsequently demonstrated that the depletion of AE2 in ESCC cells enhanced cell migration and suppressed the induction of apoptosis (Shiozaki et al., 2018a). The microarray analysis of AE2-depleted ESCC cells also showed the changes expression of various matrix met alloproteinase (MMP) signaling pathway-related genes. The expression levels of MMP1 and MMP12 mRNA were higher, and mRNA of tissue inhibitor of metalloproteinase 4 (TIMP4), metalloproteinase inhibitor, was lower in AE2-depleted ESCC cells, suggesting that MMP regulation is a key mechanism by which AE2 controls the movement of ESCC cells. Further, IHC staining revealed a relationship between the weak expression of AE2 at the invasive front and shorter postoperative survival in ESCC patients (Shiozaki et al., 2018a).

NHE plays a role in the regulation of intracellular $\mathrm{pH}$ by mediating the coupled counter-transport of one $\mathrm{H}^{+}$for one $\mathrm{Na}^{+}$. Goldman et al. (2011) demonstrated that NHE controlled deoxycholic acid-induced apoptosis in EAC cells via a $\mathrm{H}^{+}$activated, $\mathrm{Na}^{+}$-dependent ionic shift. Guan et al. (2014) reported the strong expression of NHE1 in EAC tissues, and showed that the knockdown of NHE1 in EC cells reduced their viability and induced apoptosis. We also demonstrated the inhibition of apoptosis and activation of PI3K/Akt signaling in ESCC cells following the knockdown of NHE1 (Ariyoshi et al., 2017) in ESCC. These findings indicated that the Notch signaling pathway was inhibited by the knockdown of NHE1, while IHC of primary ESCC samples showed a lower survival rate in the NHE1 low group than in the NHE1 high group (Ariyoshi et al., 2017). Liu et al. (2008) reported the significant suppression of the malignant behavior of human GC cells, the inhibition of cell growth, the induction of cell apoptosis, and the partial reversal of the malignant phenotypes of SGC-7901 following NHE1 antisense gene transfection.
TABLE 5 | Overview of $\mathrm{pH}$ regulators with roles in the cell death and survival of upper gastrointestinal tract cancers.

\begin{tabular}{|c|c|c|c|c|}
\hline Channels & Organ & $\begin{array}{c}\text { Mechanism/ } \\
\text { pathway }\end{array}$ & Induction & References \\
\hline \multirow[t]{2}{*}{$\mathrm{AE} 1$} & ESCC & $\begin{array}{c}\text { MAPK and } \\
\text { Hedgehog signaling } \\
\text { pathways }\end{array}$ & siRNA technology & $\begin{array}{c}\text { Shiozaki et al., } \\
2017\end{array}$ \\
\hline & GC & p16 & siRNA technology & $\begin{array}{l}\text { Shen et al., } \\
2007\end{array}$ \\
\hline AE2 & ESCC & & siRNA technology & $\begin{array}{c}\text { Shiozaki et al., } \\
2018 a\end{array}$ \\
\hline \multirow[t]{4}{*}{ NHE1 } & EAC & & Deoxycholic acid & $\begin{array}{c}\text { Goldman et al., } \\
2011\end{array}$ \\
\hline & EAC & & $\begin{array}{c}\text { Amiloride, } \\
\text { Guggulsterone }\end{array}$ & $\begin{array}{c}\text { Guan et al., } \\
2014\end{array}$ \\
\hline & ESCC & $\begin{array}{l}\text { PI3K-AKT signaling, } \\
\text { Notch signaling }\end{array}$ & siRNA technology & $\begin{array}{c}\text { Ariyoshi et al., } \\
2017\end{array}$ \\
\hline & GC & & Antisense gene & Liu et al., 2008 \\
\hline \multirow[t]{3}{*}{ V-ATPase } & $\mathrm{GC}$ & & $\begin{array}{l}\text { Proton pump } \\
\text { inhibitors }\end{array}$ & $\begin{array}{l}\text { Chen et al., } \\
2009\end{array}$ \\
\hline & GC & $\begin{array}{c}\text { Phosphorylation of } \\
\text { LRP6, } \\
\text { Wnt/ } \beta \text {-catenin } \\
\text { signaling }\end{array}$ & Diphyllin & $\begin{array}{l}\text { Shen et al., } \\
2011\end{array}$ \\
\hline & GC & & Pantoprazole & $\begin{array}{c}\text { Shen et al., } \\
2013\end{array}$ \\
\hline
\end{tabular}

ESCC, esophageal squamous cell carcinoma; EAC, esophageal adenocarcinoma; GC, gastric cancer.

V-ATPase is a proton pump in cells that is important for the maintenance of intracellular pH. Chen et al. (2009) showed that proton pump inhibitors (PPIs) reduced intracellular $\mathrm{pH}$ in SGC7901, human GC cell line, by suppressing V-ATPase and also promoted the apoptotic effects of antitumor drug, adriamycin. They showed that administration of adriamycin after PPI pretreatment produced the most cytotoxic effects on SGC7901 cells and increased the early and total apoptosis rates. PPI also significantly reduced the adriamycin-releasing index and increased the intracellular adriamycin concentration. Shen et al. (2011) demonstrated that diphyllin, a new V-ATPase inhibitor, decreased intracellular $\mathrm{pH}$ and induced apoptosis by inhibiting the phosphorylation of low-density lipoprotein receptor-related protein 6 (LRP6) in $\mathrm{Wnt} / \beta$-catenin signaling. They subsequently reported that pantoprazole induced the apoptosis of GC cells, and indicated the potential of pantoprazole as a V-ATPase inhibitor for the treatment of GC through the suppressed phosphorylation of LRP6 in Wnt/ $\beta$-catenin signaling (Shen et al., 2013).

Collectively, these findings indicate the potential of $\mathrm{pH}$ regulators, including AEs, NHEs, and V-ATPases, as key therapeutic targets, and the silencing of their expression may represent a novel therapeutic strategy against UGI cancers.

\section{CONCLUSION}

There is recent considerable emphasis on determining better treatment strategies for advanced cancers with poor prognosis. 
UGI cancers are aggressive, rapidly metastasize and still have low survival rate, especially for ESCC. Further, disseminated metastasis is one of the most common forms of recurrence of disease and is associated with a poor prognosis in GC patients. Therefore, detecting effective targets for UGI cancers is crucial for improving treatment options. Current information on advances in cellular physiological research on the roles of ion and water channels/transporters in the cell death and survival of UGI cancers was systematically reviewed herein. Human EC and GC express many different ion channels, AQPs, and $\mathrm{pH}$ regulators, the pharmacological manipulation and gene silencing of which affected apoptosis, and may be involved in tumorigenesis and progression. The findings of previous studies indicate the roles of ion transporter, water channels, and $\mathrm{pH}$ regulators as functional biomarkers and therapeutic targets in EC and GC. One of the powerful charms of the research in this field is that anti-cancer effect has been newly identified in several inhibitors or stimulators of ion channels, such as lubiprostone, tranilast, amlodipine, verapamil, and PPI, which

\section{REFERENCES}

Almasi, S., Kennedy, B. E., El-Aghil, M., Sterea, A. M., Gujar, S., Partida-Sanchez, S., et al. (2018). TRPM2 channel-mediated regulation of autophagy maintains mitochondrial function and promotes gastric cancer cell survival via the JNKsignaling pathway. J. Biol. Chem. 293, 3637-3650. doi: 10.1074/jbc.M117. 817635

Anderson, K. J., Cormier, R. T., and Scott, P. M. (2019). Role of ion channels in gastrointestinal cancer. World J. Gastroenterol. 25, 5732-5772. doi: 10.3748/wjg. v25.i38.5732

Ando, N., Kato, H., Igaki, H., Shinoda, M., Ozawa, S., Shimizu, H., et al. (2012). A randomized trial comparing postoperative adjuvant chemotherapy with cisplatin and 5-fluorouracil versus preoperative chemotherapy for localized advanced squamous cell carcinoma of the thoracic esophagus (JCOG9907). Ann. Surg. Oncol. 19, 68-74. doi: 10.1245/s10434-011-2049-9

Ariyoshi, Y., Shiozaki, A., Ichikawa, D., Shimizu, H., Kosuga, T., Konishi, H., et al. (2017). $\mathrm{Na}+/ \mathrm{H}+$ exchanger 1 has tumor suppressive activity and prognostic value in esophageal squamous cell carcinoma. Oncotarget 8, 2209-2223. doi: 10.18632/oncotarget.13645

Bray, F., Ferlay, J., Soerjomataram, I., Siegel, R. L., Torre, L. A., and Jemal, A. (2018). Global cancer statistics 2018: GLOBOCAN estimates of incidence and mortality worldwide for 36 cancers in 185 countries. CA. Cancer J. Clin. 68, 394-424. doi: 10.3322/caac.21492

Brenner, H., Rothenbacher, D., and Arndt, V. (2009). Epidemiology of stomach cancer. Methods Mol. Biol. 472, 467-477. doi: 10.1007/978-1-603 27-492-0_23

Chen, M., Zou, X., Luo, H., Cao, J., Zhang, X., Zhang, B., et al. (2009). Effects and mechanisms of proton pump inhibitors as a novel chemosensitizer on human gastric adenocarcinoma (SGC7901) cells. Cell. Biol. Int. 33, 1008-1019. doi: 10.1016/j.cellbi.2009.05.004

Chow, J., Norng, M., Zhang, J., and Chai, J. (2007). TRPV6 mediates capsaicininduced apoptosis in gastric cancer cells-mechanisms behind a possible new "hot" cancer treatment. Biochim. Biophys. Acta. 1773, 565-576. doi: 10.1016/j. bbamcr.2007.01.001

Cikutović-Molina, R., Herrada, A. A., Gonzalez, W., Brown, N., and Zuniga, L. (2019). TASK-3 gene knockdown dampens invasion and migration and promotes apoptosis in KATO III and MKN-45 human gastric adenocarcinoma cell lines. Int. J. Mol. Sci. 20:6077. doi: 10.3390/ijms20236077

Ding, M., Wang, H., Qu, C., Xu, F., Zhu, Y., Lv, G., et al. (2018). Pyrazolo[1,5a]pyrimidine TRPC6 antagonists for the treatment of gastric cancer. Cancer Lett. 432, 47-55. doi: 10.1016/j.canlet.2018.05.041 have been used to treat patients with other disorders, and their safeties for clinical use has already been demonstrated. In addition, the targeting of ion and water channels specifically activated in CSCs may become an important strategy for cancer therapy. On the other hand, there are inborn limitations of the review, such as the lack of a critical view of these channels in the current clinical oncology field. A more detailed understanding of the molecular mechanisms regulating cell death and survival may result in the application of cellular physiological strategies, such as the regulation of ion transporters, water channels, and intracellular $\mathrm{pH}$, as novel therapeutic approaches for UGI cancers.

\section{AUTHOR CONTRIBUTIONS}

AS wrote the manuscript. YM and EO edited the manuscript. All authors contributed to the article and approved the submitted version.

Enyedi, P., and Czirjak, G. (2010). Molecular background of leak K + currents: Two-pore domain potassium channels. Physiol Rev. 90, 559-605. doi: 10.1152/ physrev.00029.2009

Goldman, A., Chen, H., Khan, M. R., Roesly, H., Hill, K. A., Shahidullah, M., et al. (2011). The $\mathrm{Na}+/ \mathrm{H}+$ exchanger controls deoxycholic acid-induced apoptosis by a $\mathrm{H}+$-activated, $\mathrm{Na}+$-dependent ionic shift in esophageal cells. PLoS One 6:e23835. doi: 10.1371/journal.pone.0023835

Guan, B., Hoque, A., and Xu, X. (2014). Amiloride and guggulsterone suppression of esophageal cancer cell growth in vitro and in nude mouse xenografts. Front. Biol. (Beijing) 9, 75-81. doi: 10.1007/s11515-014-1289-Z

Han, Y., Shi, Y., Han, Z., Sun, L., and Fan, D. (2007). Detection of potassium currents and regulation of multidrug resistance by potassium channels in human gastric cancer cells. Cell. Biol. Int. 31, 741-747. doi: 10.1016/j.cellbi.2007. 01.008

Hartgrink, H. H., Jansen, E. P., van Grieken, N. C., and van de Velde, C. (2009). J. Gastric. Cancer. Lancet. 37, 477-490. doi: 10.1016/S0140-6736(09)60 617-6

Jemal, A., Bray, F., Center, M. M., Ferlay, J., Ward, E., and Forman, D. (2011). Global cancer statistics. CA. Cancer J. Clin. 61, 69-90. doi: 10.3322/caac.20107

Jiang, B., Li, Z., Zhang, W., Wang, H., Zhi, X., Feng, J., et al. (2014). miR-874 Inhibits cell proliferation, migration and invasion through targeting aquaporin3 in gastric cancer. J. Gastroenterol. 49, 1011-1025. doi: 10.1007/s00535-0130851-9

Kamangar, F., Dores, G. M., and Anderson, W. F. (2006). Patterns of cancer incidence, mortality, and prevalence across five continents: Defining priorities to reduce cancer disparities in different geographic regions of the world. J. Clin. Oncol. 24, 2137-2150. doi: 10.1200/JCO.2005.05.2308

Katsurahara, K., Shiozaki, A., Kosuga, T., Kudou, M., Shoda, K., Arita, T., et al. (2020). ANO9 regulated cell cycle in human esophageal squamous cell carcinoma. Ann. Surg. Oncol. 27, 3218-3230. doi: 10.1245/s10434-02008368-y

Katsurahara, K., Shiozaki, A., Kosuga, T., Shimizu, H., Kudou, M., Arita, T., et al. (2021). ANO9 regulates PD-L2 expression and binding ability to PD-1 in gastric cancer. Cancer Sci. doi: 10.1111/cas.14796 [Epub ahead of print].

Kim, M. C., Lee, H. J., Lim, B., Ha, K. T., Kim, S. Y., So, I., et al. (2014). Quercetin induces apoptosis by inhibiting MAPKs and TRPM7 channels in AGS cells. Int. J. Mol. Med. 33, 1657-1663. doi: 10.3892/ijmm.2014.1704

Kobayashi, T., Shiozaki, A., Nako, Y., Ichikawa, D., Kosuga, T., Shoda, K., et al. (2018). Chloride intracellular channel 1 as a switch among tumor behaviors in human esophageal squamous cell carcinoma. Oncotarget 9, 23237-23252. doi: 10.18632 /oncotarget.25296 
Konishi, T., Shiozaki, A., Kosuga, T., Kudou, M., Shoda, K., Arita, T., et al. (2019). LRRC8A expression influences growth of esophageal squamous cell carcinoma. Am. J. Pathol. 189, 1973-1985. doi: 10.1016/j.ajpath.2019.06.006

Kudou, M., Shiozaki, A., Yamazato, Y., Katsurahara, K., Kosuga, T., Shoda, K., et al. (2019). The expression and role of TRPV2 in esophageal squamous cell carcinoma. Sci. Rep. 9:16055. doi: 10.1038/s41598-019-5 2227-0

Kusayama, M., Wada, K., Nagata, M., Ishimoto, S., Takahashi, H., Yoneda, M., et al. (2011). Critical role of aquaporin 3 on growth of human esophageal and oral squamous cell carcinoma. Cancer Sci. 102, 1128-1136. doi: 10.1111/j.13497006.2011.01927.x

Lastraioli, E., Iorio, J., and Arcangeli, A. (2015). Ion channel expression as promising cancer biomarker. Biochim. Biophys. Acta. 1848, 2685-2702. doi: 10.1016/j.bbamem.2014.12.016

Li, B. P., Mao, Y. T., Wang, Z., Chen, Y. Y., Wang, Y., Zhai, C. Y., et al. (2018). CLIC1 promotes the progression of gastric cancer by regulating the MAPK/AKT pathways. Cell. Physiol. Biochem. 46, 907-924. doi: 10.1159/ 000488822

Li, Y., Zhu, C. L., Nie, C. J., Li, J. C., Zeng, T. T., Zhou, J., et al. (2013). Investigation of tumor suppressing function of CACNA2D3 in esophageal squamous cell carcinoma. PLoS One 8:e60027. doi: 10.1371/journal.pone.006 0027

Liu, H. F., Teng, X. C., Zheng, J. C., Chen, G., and Wang, X. W. (2008). Effect of NHE1 antisense gene transfection on the biological behavior of SGC-7901 human gastric carcinoma cells. World J. Gastroenterol. 14, 2162-2167. doi: 10.3748/wjg.14.2162

Ma, G., Liu, H., Hua, Q., Wang, M., Du, M., Lin, Y., et al. (2017). KCNMA1 cooperating with PTK2 is a novel tumor suppressor in gastric cancer and is associated with disease outcome. Mol. Cancer 16:46. doi: 10.1186/s12943-0170613-z

Ma, P. F., Chen, J. Q., Wang, Z., Liu, J. L., and Li, B. P. (2012). Function of chloride intracellular channel 1 in gastric cancer cells. World J. Gastroenterol. 18, 3070-3080. doi: 10.3748/wjg.v18.i24.3070

Matsumoto, Y., Shiozaki, A., Kosuga, T., Kudou, M., Shimizu, H., Arita, T., et al. (2021). Expression and role of CFTR in human esophageal squamous cell carcinoma. Ann. Surg. Oncol. (in press). doi: 10.1245/s10434-021-09752-y

Mitsuda, M., Shiozaki, A., Kudou, M., Shimizu, H., Arita, T., Kosuga, T., et al. (2021). Functional analysis and clinical significance of chloride channel 2 expression in esophageal squamous cell carcinoma. Ann. Surg. Oncol. doi: 10. 1245/s10434-021-09659-8 [Epub ahead of print].

Nagaraju, G. P., Basha, R., Rajitha, B., Alese, O. B., Alam, A., Pattnaik, S., et al. (2016). Aquaporins: their role in gastrointestinal malignancies. Cancer Lett. 373, 12-18. doi: 10.1016/j.canlet.2016.01.003

Nashimoto, A., Akazawa, K., Isobe, Y., Miyashiro, I., Katai, H., Kodera, Y., et al. (2013). Gastric cancer treated in 2002 in Japan: 2009 annual report of the JGCA nationwide registry. Gastric. Cancer. 16, 1-27. doi: 10.1007/s10120-012-0 $163-4$

Nie, C., Qin, X., Li, X., Tian, B., Zhao, Y., Jin, Y., et al. (2019). CACNA2D3 enhances the chemosensitivity of esophageal squamous cell carcinoma to cisplatin via inducing $\mathrm{Ca}(2+)$-mediated apoptosis and suppressing PI3K/Akt Pathways. Front. Oncol. 9:185. doi: 10.3389/fonc.2019.00185

Okada, Y., Maeno, E., Shimizu, T., Dezaki, K., Wang, J., and Morishima, S. (2001). Receptor-mediated control of regulatory volume decrease (RVD) and apoptotic volume decrease (AVD). J. Physiol. 532, 3-16. doi: 10.1111/j.1469-7793.2001. 0003g.X

Okada, Y., Shimizu, T., Maeno, E., Tanabe, S., Wang, X., and Takahashi, N. (2006). Volume-sensitive chloride channels involved in apoptotic volume decrease and cell death. J. Membr. Biol. 209, 21-29. doi: 10.1007/s00232-005-0836-6

Pardo, L. A., and Stuhmer, W. (2014). The roles of $\mathrm{K}(+)$ channels in cancer. Nat. Rev. Cancer. 14, 39-48. doi: 10.1038/nrc3635

Pedersen, S. F., and Stock, C. (2013). Ion channels and transporters in cancer: pathophysiology, regulation, and clinical potential. Cancer Res. 73, 1658-1661. doi: 10.1158/0008-5472.CAN-12-4188

Qiu, Z., Dubin, A. E., Mathur, J., Reddy, K., Miraglia, L. J., Reinhardt, J., et al. (2014). SWELL1, a plasma membrane protein, is an essential component of volume-regulated anion channel. Cell 157, 447-458. doi: 10.1016/j.cell.2014.03. 024
Schreiber, R., Uliyakina, I., Kongsuphol, P., Warth, R., Mirza, M., Martins, J. R., et al. (2010). Expression and function of epithelial anoctamins. J. Biol. Chem. 285, 7838-7845. doi: 10.1074/jbc.M109.065367

Seo, Y., Choi, J., Lee, J. H., Kim, T. G., Park, S. H., Han, G., et al. (2020). Diversity-oriented generation and biological evaluation of new chemical scaffolds bearing a 2,2-dimethyl-2H-chromene unit: Discovery of novel potent ANO1 inhibitors. Bioorg. Chem. 101:104000. doi: 10.1016/j.bioorg.2020.10 4000

Shao, X. D., Wu, K. C., Guo, X. Z., Xie, M. J., Zhang, J., and Fan, D. M. (2008). Expression and significance of HERG protein in gastric cancer. Cancer Biol. Ther. 7, 45-50. doi: 10.4161/cbt.7.1.5126

Shao, X. D., Wu, K. C., Hao, Z. M., Hong, L., Zhang, J., and Fan, D. M. (2005). The potent inhibitory effects of cisapride, a specific blocker for human ether-a-gogo-related gene (HERG) channel, on gastric cancer cells. Cancer Biol. Ther. 4, 295-301. doi: 10.4161/cbt.4.3.1500

Shen, W., Zou, X., Chen, M., Liu, P., Shen, Y., Huang, S., et al. (2011). Effects of diphyllin as a novel V-ATPase inhibitor on gastric adenocarcinoma. Eur. J. Pharmacol. 667, 330-338. doi: 10.1016/j.ejphar.2011.05.042

Shen, W., Zou, X., Chen, M., Shen, Y., Huang, S., Guo, H., et al. (2013). Effect of pantoprazole on human gastric adenocarcinoma SGC7901 cells through regulation of phosphor-LRP6 expression in Wnt/ $\beta$-catenin signaling. Oncol. Rep. 30, 851-855. doi: 10.3892/or.2013.2524

Shen, W. W., Wu, J., Cai, L., Liu, B. Y., Gao, Y., Chen, G. Q., et al. (2007). Expression of anion exchanger 1 sequestrates p16 in the cytoplasm in gastric and colonic adenocarcinoma. Neoplasia 9, 812-819. doi: 10.1593/neo.07403

Shimizu, H., Shiozaki, A., Ichikawa, D., Fujiwara, H., Konishi, H., Ishii, H., et al. (2014). The expression and role of aquaporin 5 in esophageal squamous cell carcinoma. J. Gastroenterol. 49, 655-666. doi: 10.1007/s00535-013-0827-9

Shiozaki, A., Hikami, S., Ichikawa, D., Kosuga, T., Shimizu, H., Kudou, M., et al. (2018a). Anion exchanger 2 suppresses cellular movement and has prognostic significance in esophageal squamous cell carcinoma. Oncotarget 9, 2599326006. doi: 10.18632/oncotarget.25417

Shiozaki, A., Ichikawa, D., Otsuji, E., and Marunaka, Y. (2014). Cellular physiological approach for treatment of gastric cancer. World J. Gastroenterol. 20, 11560-11566. doi: 10.3748/wjg.v20.i33.11560

Shiozaki, A., Katsurahara, K., Kudou, M., Shimizu, H., Kosuga, T., Ito, H., et al. (2021). Amlodipine and verapamil, voltage-gated $\mathrm{Ca}^{2+}$ channel inhibitors, suppressed the growth of gastric cancer stem cells. Ann. Surg. Oncol. doi: 10.1245/s10434-021-09645-0 [Epub ahead of print].

Shiozaki, A., Kudou, M., Fujiwara, H., Konishi, H., Shimizu, H., Arita, T., et al. (2020). Clinical safety and efficacy of neoadjuvant combination chemotherapy of tranilast in advanced esophageal squamous cell carcinoma: Phase I/II study (TNAC). Medicine (Baltimore) 99:e23633. doi: 10.1097/MD.0000000000 023633

Shiozaki, A., Kudou, M., Ichikawa, D., Fujiwara, H., Shimizu, H., Ishimoto, T., et al. (2018b). Esophageal cancer stem cells are suppressed by tranilast, a TRPV2 channel inhibitor. J. Gastroenterol 53, 197-207. doi: 10.1007/s00535-017-1 338-x

Shiozaki, A., Kudou, M., Ichikawa, D., Shimizu, H., Arita, T., Kosuga, T., et al. (2017). Expression and role of anion exchanger 1 in esophageal squamous cell carcinoma. Oncotarget 8, 17921-17935. doi: 10.18632/oncotarget.14900

Sun, W. J., Hu, D. H., Wu, H., Xiao, H., Lu, M. D., Guo, W. J., et al. (2016). Expression of AQP1 was associated with apoptosis and survival of patients in gastric adenocarcinoma. Dig. Surg. 33, 190-196. doi: 10.1159/000443843

Tachimori, Y., Ozawa, S., Numasaki, H., Ishihara, R., Matsubara, H., Muro, K., et al. (2019). Comprehensive registry of esophageal cancer in Japan, 2012. Esophagus 16, 221-245. doi: 10.1007/s10388-019-00674-z

Udagawa, H., Ueno, M., Shinohara, H., Haruta, S., Kaida, S., Nakagawa, M., et al. (2012). The importance of grouping of lymph node stations and rationale of three-field lymphadenectomy for thoracic esophageal cancer. J. Surg. Oncol. 106, 742-747. doi: $10.1002 /$ jso. 23122

Wang, H., Yang, X., Guo, Y., Shui, L., Li, S., Bai, Y., et al. (2019). HERG1 promotes esophageal squamous cell carcinoma growth and metastasis through TXNDC5 by activating the PI3K/AKT pathway. J. Exp. Clin. Cancer Res. 38:324. doi: 10.1186/s13046-019-1284-y

Wu, J., Zhang, Y. C., Suo, W. H., Liu, X. B., Shen, W. W., Tian, H., et al. (2010). Induction of anion exchanger- 1 translation and its opposite roles in the 
carcinogenesis of gastric cancer cells and differentiation of K562 cells. Oncogene 29, 1987-1996. doi: 10.1038/onc.2009.481

Xia, J., Wang, H., Li, S., Wu, Q., Sun, L., Huang, H., et al. (2017). Ion channels or aquaporins as novel molecular targets in gastric cancer. Mol. Cancer. 1:54. doi: 10.1186/s12943-017-0622-y

Xie, R., Liu, L., Lu, X., and Hu, Y. (2020). LncRNA OIP5-AS1 facilitates gastric cancer cell growth by targeting the miR-422a/ANO1 axis. Acta Biochim. Biophys. Sin. (Shanghai) 52, 430-438. doi: 10.1093/abbs/gmaa 012

Yamazato, Y., Shiozaki, A., Ichikawa, D., Kosuga, T., Shoda, K., Arita, T., et al. (2018). Aquaporin 1 suppresses apoptosis and affects prognosis in esophageal squamous cell carcinoma. Oncotarget 9, 29957-29974. doi: 10. 18632/oncotarget. 25722

Yu, L., Li, H., Li, Z., Jia, J., Wu, Z., Wang, M., et al. (2020). Long non-coding RNA HAND2-AS1 inhibits growth and migration of gastric cancer cells through regulating the miR-590-3p/KCNT2 Axis. Onco. Targets Ther. 13, 3187-3196. doi: 10.2147/OTT.S233256

Zhang, R., Tian, P., Chi, Q., Wang, J., Wang, Y., Sun, L., et al. (2012). Human ethera-go-go-related gene expression is essential for cisplatin to induce apoptosis in human gastric cancer. Oncol. Rep. 27, 433-440. doi: 10.3892/or.2011. 1515

Zhao, K., Wang, Z., Li, X., Liu, J. L., Tian, L., and Chen, J. Q. (2019). Exosomemediated transfer of CLIC1 contributes to the vincristine-resistance in gastric cancer. Mol. Cell. Biochem. 462, 97-105. doi: 10.1007/s11010-019-03613-9

Zhu, H., Wu, Y., Kang, M., and Zhang, B. (2020). MiR-877 suppresses gastric cancer progression by downregulating AQP3. J. Int. Med. Res. 48:300060520903661. doi: $10.1177 / 0300060520903661$

Conflict of Interest: The authors declare that the research was conducted in the absence of any commercial or financial relationships that could be construed as a potential conflict of interest.

Copyright (c) 2021 Shiozaki, Marunaka and Otsuji. This is an open-access article distributed under the terms of the Creative Commons Attribution License (CC BY). The use, distribution or reproduction in other forums is permitted, provided the original author(s) and the copyright owner(s) are credited and that the original publication in this journal is cited, in accordance with accepted academic practice. No use, distribution or reproduction is permitted which does not comply with these terms. 